\title{
The Role of International Alert in Advancing Early Warning and Early Action
}

\author{
Kumar Rupesinghe
}

\begin{abstract}
This paper focuses on the role of International Alert in promoting early warming and early action in areas of international conflict. It begins by introducing the percepts of preventive diplomacy as used by International Alert. A number of the organisation's objectives and activities are highlighted, showing the many ways in which the principles of conflict prevention and early warning are being developed in areas of potential violence and amongst a wider interdisciplinary audience. In conclusion, the main aims of International Alert and our objective to create a global network with different sectors of the international community and to motivate the creation of a non-military early action mechanism to prevent the escalation of violent conflict are presented.
\end{abstract}

\section{Résumé}

Cet article fait état du rôle joué par International Alert en matière d'alerte préventive et d'intervention rapide dans des situations de conflits internes. Dans un premier temps, les principes de la diplomatie préventive tels que mis en oeuvre par International Alert sont présentés. Un certain nombre d'objectifs et $d^{\prime}$ activités de cette organisation sont ensuite mis en lumière, illustrant les multiples façons dont les principes en matière de prévention des conflits et d'alerte rapide peuvent être exploités dans les situations de violence potentielle et la façon dont ces notions peuvent être discutées au sein d'un public varié. En conclusion, les objectifs fondamentaux d'International Alert et le projet de créer un Réseau global sont

Kumar Rupensinghe, Director, International Alert, London, England.

Researched and edited by Sanam Anderlini, with acknowledgements to Jeremy Bristol. présentés. Ce dernier, en réunissant les divers secteurs de la communauté internationale impliqués en matière d'alerte préventive, vise à répondre à la nécessité de créer un mécanisme non-militaire destinéà prévenir l'éclatement et la propagation des conflits violents.

\section{Introduction}

In 1985, a small group of scholars and human rights activists headed by Martin Ennals, founder of Amnesty International, recognised that far too often conflicts within a country undermine efforts to protect human rights and promote sustainable development. Globally, there was evidence to suggest that inter-state wars were decreasing, but there were dangerous signs of intra-state conflicts increasing. Conflicts rooted in identity, and unresolved disputes that had been suppressed during the Cold War period, were emerging. The United Nations, whose prime function is to arbitrate and mediate in international disputes, was unlikely to intervene successfully in internal conflicts for which it had no mandate at all. So it was evident that the world had no structure or procedure through which these future wars could be prevented or resolved. International Alert was founded as an action-based non-governmental institution devoted to the study of internal conflicts, preventive diplomacy, and early warning systems which could help identify tensions and avert potential crises.

\section{Preventive Diplomacy}

Preventive diplomacy is a strategy to prevent the outbreak and escalation of violence in conflict. As developed by International Alert (IA) and others in the field of conflict prevention, preventive diplomacy arises out of the failure of traditional forms of state-based international diplomacy in dealing with internal conflicts. There are a number of key issues that can be raised here. First, though they are in many ways more complex than inter-state conflicts, it is still possible to prevent internal conflicts and to end violence. Prevention, however, requires carefully developed strategic contingency plans that take account of military and non-military responses. Second, the lack of action and a failure of political will often allow conflicts to drag on. Inherent to political will is the question of selectivity. The international community may mobilise its forces to intervene in Bosnia based on media attention, geographical proximity, or powerful lobby groups in the United States or Europe, but the lack of any such external pressure can isolate a country like Burundi and allow governments to use the principle of sovereignty to justify their doing nothing.

The recognition of a sovereign government is a fundamental obstacle to intervention in internal conflicts. External governments and the UN can only become involved if they are officially invited (UN Charter Art.II.vii). If there is no state consent to intervention, then there is less chance of access to all parties involved in the conflict. Conversely, intervention by one agency alone will not resolve the conflict. Many of those who have tried to intervene have later been accused of abandoning their neutrality. The United Nations, for example, is often viewed with suspicion because of its strong governmental links. It is therefore essential that governmental and non-governmental institutions try to cooperate and complement each other's efforts and so as to mitigate biases as much as possible.

This leads to a final consideration, which is the need for a structured approach to prevention. The structured approach refers to a well coordinated

Refuge, Vol. 15, No. 4 (1996) 
multi-track action mechanism, based on a division of labour that draws upon the comparative advantages and strengths of each agency. It recognises and addresses the different levels of conflict that need attention and has been described as " $a$ web of interconnected parts (activities, individuals, institutions, communities) that operate together, whether awkwardly or gracefully, for a common goal: A world at peace" (Diamond and McDonald 1993). This perspective is substantially different from traditional military responses, for it advocates a strategic coalition between inter-governmental, governmental and non-governmental agencies in conjunction with local peace constituencies and other relevant actors.

\section{Early Warning and Preventive Diplomacy}

By definition, preventive action is a response to warnings. Many of the early warning systems that already function efficiently are geared to identifying potential refugee flows, so that effective contingency plans can be activated. In the field of conflict prevention, however, early warning is concerned with the ability to forecast potential conflicts. It is based on information gathering, informal and formal fact-finding, and, most importantly, a system of synthesising the data with political indicators to assess and analyse the threat to peace and the action that needs to be taken (Boutros-Ghali 1992). Contingency planning for victims is part of the system, but the prime focus is victim prevention.

Early warning as a tool for conflict prevention requires regular monitoring and updating of a situation. A flow of information is essential to an early warning system, but the gathering of that information and subsequent analysis can raise problems. For a start, intelligence systems are geared to national security. It is also understandable that within undemocratic regimes, people are suspicious of any attempts to develop new intelligence systems as these regimes often use their intelligence networks to identify signs of organised resistance. Consequently, it is essential that the primary aim of any system is the protection of vulnerable sectors of society against gross human rights violations, terror, genocide or politicide. The intention is to predict trends leading to an escalation in violence, long before the violence becomes a reality. The objective is to initiate a proactive response to the conflict, using a network of regional and local NGOs and civic groups.

\section{The Role of International Alert}

The role of International Alert in advancing early warning and early action is twofold. On the one hand IA, though not primarily an early warning agency itself, has pioneered and advocated a commitment to early warning and preventive action. A number of published research papers discussing the concept of early warning, and surrounding issues, have been influential in the field of conflict prevention and amongst a wide inter-disciplinary audience. ${ }^{1}$ More recent theoretical developments are discussed below. In addition, IA has acted as a catalyst to encourage inter-governmental bodies and other humanitarian and development institutions to recognise the need for an early warning system. A number of these activities are outlined at a later stage in this paper.

IA's conceptual approach to early warning is multi-faceted. First, we believe that a single monolithic global early warning system is an unlikely development; rather, an effective system would be a function of a series of smaller networks. Furthermore, there is a danger of an 'information glut,' resulting in too many people being 'warned' of too many things, but not enough people being able to take the necessary actions. This is predominantly due to the fact that most organisations are unwilling to take action based on information gathered by others, so ownership of the information plays a key role in promoting action.

Ironically, despite the abundance of information, much needs to be improved in the area of data collection. Unfortunately, there is still a lack of coordination between information gatherers, who vary from being members of Non-governmental Organizations (NGOs) and Inter-governmental Organizations (IGOs) through to church organisations, the media, and others. In addition, there is still a gap between quantitative data analysis and more qualitative, narrative-based reports. Quantitative analysis can be useful in monitoring and recognising the trends, particularly where figures of human rights violations are shown, but they have limited impact when political decisions need to be taken. This is a key problem in any discussion about the role of early action mechanisms, for it refers to the lack of co-ordination between early warning and early action. It also raises other questions regarding the nature of the action that needs to be taken and the time frame that needs to be in place at each stage of managing the conflict.

\section{Co-ordination, Complementarity, and Capacity-building}

At present, joint action is not, for the most part, being taken. This problem arises out of a number of practical considerations. First, many NGOs are limited by their mandates. For example, the International Committee of the Red Cross has its own information gathering system, but cannot share this openly with other NGOs, nor can it act on data provided by others. Second, every organisation has its priorities. Amnesty International's focus on Nigeria at a particular time, for example, may not bear relevance to Oxfam's programme, which may be simultaneously focused on India. It is therefore necessary to develop means through which organisations are themselves involved in the gathering and 'owning' of information. A recent study concluded by the Netherlands Institute of International Relations confirms this. While examining the early warning and preventive actions of a number of inter-governmental organisations, the lack of effectiveness and cohesion in their operations was revealed. No well-developed early warning systems have yet been devel- 
oped although many organisations such as the Organization for Security and Co-operation in Europe (OSCE), Association of South East Asian Nations, (ASEAN), United Nations (UN), Economic Community of West African States (ECOWAS), and Organization of African Unity (OAU), are aware of the need for such a system (Siccama et al. 1996)

There is still a need for the coordination of data collectors at the theoretical level. In other words, it is important to agree on a set of definitions for terms and concepts such as "conflict," "serious dispute," "potential conflict" and others that are often inter-changed. Secondly, an agreed upon set of indicators must be developed and tested by data collectors. Thirdly, standardised reporting formats should be developed to ease the exchange of information. Finally, IA is interested in the creation of an early warning clearing house which could collect and disseminate regular early warning data to a network of early action agencies. With access to information databases worldwide and a range of web sites on the Internet, the clearing house could synthesise the information gathered and offer a range of standardised reports on subjects such as countries at war, potential conflicts, minorities at risk, as well as thematic issues such as arms proliferation. The clearing house could also act as a referral system, with information on recognised experts and information brokers who could provide more in-depth analysis.

The early action network should be comprised of human rights organisations, humanitarian agencies, development agencies, governments, regional and global inter-governmental organisations such as the OAU, European Union (EU), and UN, the corporate sector, and the academic community amongst others. The aim would be to ensure that a diverse set of organisations have access to regular and reliable information about ongoing and potential conflicts, allowing them to determine a coordinated plan of early preventive action.
Through coordination, there is also complementarity and a structured division of labour. This has two main results. First, the early action network would be decentralised, so that for each region or country only a selected group would be involved in planning strategic action. This is efficient, as those actors with a particular interest or involvement in a region will be more willing to take early preventive action. Secondly, a cooperative division of labour would permit each agency to concentrate on its areas of strength and not be forced to deal with the complexity of a conflict in its entirety. For example, agencies with strong governmental ties could focus on advocacy, while others inform the media; those with local connections and facilities could concentrate on activating support in the conflict area. Furthermore, IA is currently encouraging the development of national coalitions of NGOs to work on specific regional or thematic issues. This gives NGOs a more unified and influential voice, thus enabling them to take more effective action.

The current lack of action also stems from another problem. It is often assumed that a good early warning system amongst the rich nations in the "North" will lead to preventive action by local actors in the "South." The warning of potential violence by external forces, however, will not quell the tension and conflict which exists in a country. It is therefore, necessary to develop early warning and preventive action mechanisms that draw on external and internal capabilities. Strengthening grassroots and civic movements, assisting them in handling their own early warning systems and developing regional focal points, and working with organisations such as the OAU and regional African NGOs are intrinsic to IA's approach.

As a means of developing and strengthening grassroots involvement in peace-building, IA organises training seminars and workshops for local communities in conflict areas. The programmes have both long- and shortterm objectives. On the one hand, training programmes aim to introduce the concepts of multi-track diplomacy to those directly affected by violence. The purpose is to encourage locals to participate in peace-building initiatives and to explore ways in which violent conflict can be transformed peacefully. On the other hand, the long-term objectives of training and capacity building are intended to enable local actors to take more decisive action against the surge of violence at an earlier stage. In other words, grassroots capacity building is an early action to ensure that early warning of violent conflict will not be necessary in the future.

\section{IA's Practical Approach}

In its efforts to encourage the development of a truly global network of early preventive action, IA has sponsored and participated in a number of regional conferences focusing on the issues surrounding early warning mechanisms. The aim of such conferences is to introduce the principles of prevention to a wider audience and, as well, to encourage broader participation in the conceptual debate and practical application of preventive diplomacy.

To this effect, one aim has been to foster cooperation between NGOs and the UN. In January 1993, IA and the National Institute for Research Advancement (NIRA) of Tokyo and the United Nations University (UNU) cohosted an Expert's Round Table on Preventive Diplomacy and the UN's Agenda for Peace' (held at UN headquarters in New York). The purpose of the event was to share and evaluate experiences in preventive diplomacy, with particular reference to the UN. NGO and UN cooperation was also discussed. The following recommendations were made:

1) that the UN Secretariat undertake an initiative to integrate the early warning work that was being duplicated by the various UN agencies and to increase ties with relevant NGOs;

2) that NGOs and the academic community should participate in the 
implementation of a computerised early warning system in the Secretariat and that the monitoring of different regions be undertaken by UN staff and external experts;

3) that a 24-hour early warning centre be created to monitor reports and disseminate information to relevant senior figures in the organisation (Daws 1993).

The early warning centre is now in operation in New York. However, joint participation with outside experts is still very limited.

Such cooperative efforts comprise part of the attempt to establish an NGO platform on early warning and preventive action. In May 1995, sixty representatives from key European agencies in the fields of development and humanitarian relief, and peace, along with human rights organisations and UN agencies met in Oslo to discuss ways in which conflict prevention could be placed on the agenda in European policy. The development of an early warning platform which could gather and disseminate information regarding countries at risk was among the conference themes (Adrian-Paul 1995). In particular, a steering committee for the development of an NGO consortium was agreed upon. Links between 160 organisations are maintained through the CPEN e-mail network.

The main objective following from this conference was the creation and establishment of national platforms primarily in European countries to advocate and advance preventive diplomacy in those countries, and to develop links with NGOs specialised in particular regions and local experts. The need for greater commitment and cooperation with development, human rights and humanitarian agencies was also emphasised

Another IA sponsored conference sought to explore an interdisciplinary approach to the issues of early warning. In June 1995, the Steering Committee of the Conflict Early Warning Systems (CEWS) Research Programme met at IA's headquarters in London (CEWS is part of the International
Social Science Council). The aim was to provide a positive, interdisciplinary, social scientific response to Dr. Boutros Boutros-Ghali's Agenda for Peace. The strategy is to seek ways in which NGOs and the UN can cooperate and complement each other's activities, particularly in the development of early warning systems and preventive action. The Committee has two objectives. The first is to create and disseminate (via the Internet) a set of comparative, interdisciplinary case studies of conflict prevention successes and failures. The results will be published in a book with contributions from members of the Steering Group. Secondly, they plan to improve and extend accessibility to a database on conflict prevention, including analyses of historical cases, and conceptual developments (Alker et al. 1995).

These efforts all continue the process of developing models and addressing policy issues. In 1993, IA and the Centre for International Development (CIDCM) in Maryland jointly sponsored a workshop on the Early Warning of Communal Conflicts and Humanitarian Crises, bringing together primary and secondary data holders from a variety of disciplines. The objectives of the workshop were to discuss the issues surrounding the coordination of data collection and possible models for early warning systems. Problems of policy and lack of political will on the part of Western powers, and the need for building public awareness regarding preventive action and planning specific responses were also discussed. Six major recommendations arose from the workshop seminars:

1) Electronic networks should be developed for the sharing of early warning information;

2) Key variables must be identified in the way information is gathered and shared;

3) Researchers should establish and strengthen their networks regarding the collecting and coding of relevant information;

4) A 'common language' for classification of data must be developed;
5) The network between NGOs, researchers and activists should be broadened to include groups from within the regions of conflict;

6) A simulation meeting focused on one country or region should be held, so that NGO representatives and regional experts could engage in the early warning process.

Capacity-building in Africa, and increased communication among Africa-based NGOs, has been of particular concern. In September 1994, IA and the Ad Hoc Committee for Peace and Development of Ethiopia sponsored a joint conference on The Challenge for Peacemaking in Africa: Conflict Prevention and Conflict Resolution. Over 250 participants made up of NGO representatives, scholars, women's groups, grassroots organisations, and local and international donors attended. This was the first conference of its kind in Africa, and the cross-sectored discussions resulted in a series of recommendations. Especially with regard to early warning and conflict prevention, the following recommendations were made.

1) An information database should be created as an analytical tool for researchers and practitioners, with a strong early warning component;

2) Multi-sectored alliances need to be developed between governments, NGOs, the media and research institutions;

3) Focal points should be identified at the sub-regional level and national level and alliances formed;

4) National advocacy and early warning platforms should be formed, aimed at decision makers;

5) The early warning system should ensure that decision makers are held accountable;

6) An informal network within the NGO community should be established to build trust (International Alert 1994a).

Following from the 1994 conference, a Focal Points workshop was arranged by IA and the Inter-Africa Group bringing together participants from throughout the African continent. The purpose of the workshop was to facili- 
tate the establishment of an early warning mechanism among Africabased NGOs and to increase the capacity of localNGOs to take more decisive and effective action. Cooperation and collaboration between the NGO and inter-governmental sectors was also explored (International Alert 1994b). Several recommendations were made: 1) A new bi-monthly publication (and on-line web page), Early Warning News, produced by Inter-press Service Africa would be used as an indicator for action. Data would be gathered from various constituencies (media, church, legal and human rights organisations, academics, NGOs, and other civic groups) invited to participate in a forum for debate;

2) The UN Economic Commission for Africa and the Inter-Africa Group agreed to establish a database of local, regional, and international actors in the region;

3) The Council for the Development of Social Science Research in Africa (CODESRIA) and the Centre for Conflict Resolution (CCR) agreed to build a conflict specific core research group, allowing scholars to exchange data and making the $C C R$ resource Centre available for wider use;

4) IA agreed to hold an annual meeting between participants to discuss on-going initiatives and new developments;

5) The group plans to establish closer ties with the OAU and other regional inter-governmental fora, through regular meetings of a consultative committee;

6) The participation of women was encouraged. In particular women's roles in information dissemination should be developed.

Sub-regional focal points meetings will take place in Tunisia, West, Central, Eastern and Southern Africa in November 1996. The objectives will be to strengthen and develop platforms for early warning and early action.

In addition to these links to early warning projects in Africa, IA has been working with groups in the former
Soviet Union. IA has had close links with the network created by the Institute of Ethnology and Anthropology (IEA) of the Russian Academy of Science and the Conflict Management Group (CMG) located in the United States, since 1992. In 1995, IA undertook a feasibility study on their behalf for an early warning network in the former Soviet Union. The IEA/CMG network now has over forty members throughout the Russian Federation and CIS countries. In September 1996, network members will meet at IA headquarters in London to share experiences of early warning and discuss conflict situations in the region.

\section{Developing Common Standards and a Menu of Options}

IA's current and future work in early warning will continue to centre on the development of regional focal points and cooperation with local NGO groups. We are also involved in developing standards for reporting, assessing, and responding to early warning. Working closely with PIOOM (Dutch abbreviation for Interdisciplinary Research Program on Root Causes of Human Rights Violations) in the Netherlands, the Centre for Documentation and Research at the UNHCR, Human Rights Information and Documentation Systems International (HURIDOCS) in Geneva and the Centre for International Development and Conflict Management in Maryland, our aim is to create a standard format for monitoring, developing, and testing sets of indicators, and plan how information can be pooled or disseminated to people who can respond. A menu of options for action using the different tools and approaches of conflict prevention will also be developed and applied on a case by case basis to provide recommendations for action by internal and external parties.

In addition to being a major participant in the above gatherings, IA is also very active in the field of advocacy and lobbying of parliamentary groups and inter-governmental organisations such as the EU, OAU, and OSCE. In the EU especially, IA has been directly in- volved in promoting the concept of preventive diplomacy and a need for early warning, through the Michel Rocard initiative for the establishment of a European Analysis Centre for Active Crisis Prevention. It has also been active in the formation of the Bernard Kouchner's Parliamentary Intergroup on Crisis Prevention which meets monthly. In parallel to the Rocard Initiative, IA is jointly working with Saferworld in lobbying for conflict prevention measures to be introduced to the Common Foreign and Security Policy (CFSP) of the Maastricht Treaty which is currently being revised and reassessed (IGC began in March 1996). In May 1996, IA cohosted a conference on Conflicts in Africa with the North-South Centre and Synergies Africa (Adrian-Paul and Win 1996). The main objectives were to influence the CFSP by developing a policy framework for conflict prevention in Africa within the EU, and to develop a plan for future cooperation. IA's advocacy programme is part of a wider objective to make preventive diplomacy a strategic goal for the 21st century.

The prevention and resolution of conflicts, the establishment of early warning networks and structured action programs cannot be achieved single-handedly. It is beyond the capacity of any single organisation or indeed any single sector to realize such goals. This does not imply that prevention itself is impossible; rather, that to succeed in diffusing a potential war, coordinated efforts must be made.

\section{Notes}

1. For a comprehensive list of such papers, please contact International Alert at the address listed in the "Selected Efforts on Early Warning" elsewhere in this issue.

\section{References}

Adrian-Paul, A. 1995. NGO Coalition for Conflict Prevention-The Way Forward. International Alert.

Adrian-Paul, A., and A. Win. 1996. The European Union and the Issue of Conflicts in Africa: Peace-building, Conflict Prevention and

Continued on page 20, Col. 3/The Role of ... 